\title{
A CONSTRUÇÃO DOS PROBLEMAS SOCIAIS DO FUTEBOL: ANÁLISE DO POTENCIAL IDEOLÓGICO DE EDITORIAIS DA FOLHA DE S. PAULO
}

THE CONSTRUCTION OF SOCIAL PROBLEMS OF FOOTBALL: ANALYSIS OF THE IDEOLOGICAL POTENTIAL OF FOLHA DE S. PAULO EDITORIALS LA CONSTRUCCIÓN DE LOS PROBLEMAS SOCIALES DEL FÚTBOL: ANÁLISIS DEL POTENCIAL IDEOLÓGICO DE EDITORIALES DE FOLHA DE S. PAULO

\section{Felipe Tavares Paes Lopes'}

RESUMO: Este trabalho analisa quais aspectos do futebol foram tipificados como problemáticos em editoriais da Folha de S. Paulo durante o período de 2008 a 2017 e interpreta o caráter ideológico potencial dessas tipificações. Para tanto, adota o conceito de ideologia elaborado por John B. Thompson, que entende que uma forma simbólica pode ser caracterizada como ideológica quando estabelece e sustenta relações de dominação. Também adota a sua proposta metodológica - a hermenêutica de profundidade -, que é organizada em três fases: análise sócio-histórica, análise formal ou discursiva e interpretação/reinterpretação. Entre outras coisas, conclui que o material analisado é potencialmente ideológico porque mantém o futebol feminino e o machismo nas arquibancadas na penumbra, naturaliza a lógica neoliberal que orienta a produção do espetáculo futebolístico, contribui para fazer crer que a corrupção é um fenômeno permanente e imutável e expurga as torcidas organizadas, construindo-as como um elemento irracional no meio da coletividade torcedora.

Palavras-chave: Futebol. Ideologia. Problema social. 
ABSTRACT: This paper analyzes which aspects of football were typified as problematic in Folha de S. Paulo editorials during the period 2008 to 2017 and interprets the potential ideological of these typifications. For this, it adopts the concept of ideology elaborated by John B. Thompson, who understands that a symbolic form can be characterized as ideological when it establishes and sustains relations of domination. It also adopts his methodological proposal - depth hermeneutics -, which is organized in three phases: socio-historical analysis, formal or discursive analysis and interpretation/reinterpretation. Among other things, it concludes that the material analyzed is potentially ideological because it maintains women's football and machismo in the stands in the shadow, naturalizes the neoliberal logic that guides the production of the football spectacle, contributes to the belief that corruption is a permanent and immutable phenomenon and purges the organized groups of fans, building them as an irrational element in the midst of the fan collective.

Keywords: Football. Ideology. Social problem.

RESUMEN: Este trabajo analiza qué aspectos del fútbol fueron tipificados como problemáticos en editoriales de la Folha de São Paulo durante el período de 2008 a 2017 e interpreta el carácter ideológico potencial de esas tipificaciones. Para eso, adopta el concepto de ideología desarollado por John B. Thompson, que entiende que una forma simbólica puede ser caracterizada como ideológica cuando establece y sostiene relaciones de dominación. También adopta su propuesta metodológica - la hermenéutica de profundidad -, que se organiza en tres fases: análisis socio histórico, análisis formal o discursivo e interpretación/reinterpretación. Entre otras cosas, concluye que el material analizado es potencialmente ideológico porque mantiene el fútbol femenino y el machismo en las canchas en la penumbra, naturaliza la lógica neoliberal que orienta la producción del espectáculo futbolístico, contribuye a hacer creer que la corrupción es un fenómeno permanente e inmutable y expurga los grupos organizados de hinchas, construyéndolos como un elemento irracional en medio de la colectividad de aficionados.

Palabras clave: Fútbol. Ideología. Problema social.

\section{Introdução²}

Este trabalho aborda uma relevante questão para o campo de estudos sobre comunicação, esporte e cultura: o processo de construção dos problemas sociais do futebol. Seguindo os caminhos abertos e trilhados pelo construcionismo

\footnotetext{
2 O presente artigo é fruto de uma pesquisa que contou com auxílio da Fundação de Amparo à Pesquisa do Estado de São Paulo (Fapesp).
} 
(BEST; LOSEKE, 2003), pode-se afirmar que nenhuma condição é problemática em si mesma, mas passa a sê-la quando assim é definida por uma pessoa ou um grupo de pessoas. Com efeito, um problema social não deve ser caracterizado como um tipo de condição específica, capaz de entrar naturalmente na agenda pública e na pauta das ações políticas em função de sua extensão e gravidade. Afinal, existe uma infinidade de fenômenos com efeitos devastadores para uma parte expressiva da população que não entra nessa agenda e pauta. Ademais, as próprias noções de extensão e gravidade são subjetivas, uma vez que o que é grave e extenso para uns pode simplesmente não ser para outros.

Diante disto, entendo que problemas sociais devem ser definidos como uma classe de atividades voltada para supostas condições - que podem ser "reais" ou não. Com isso, neste trabalho, volto minha atenção para o processo social pelo qual determinadas condições do futebol brasileiro são definidas e delimitadas como problemáticas. Minha questão não é saber o que causa "objetivamente" essas condições e o que deve ser feito para eliminá-las, mas por que há uma preocupação com certas condições e não com outras e como a forma como essas condições são caracterizadas podem modelar elas próprias (BEST; LOSEKE, 2003).

A definição e a delimitação de uma questão como problema social são o resultado de um processo coletivo, que inclui diversos claims-makers ${ }^{3}$. Esses competem entre si para converter uma questão em um tópico dominante na pauta política, na agenda dos meios de comunicação e, até mesmo, nas conversas cotidianas. Entre os principais claims-makers, destacam-se os ativistas, os acadêmicos e a mídia. Essa última é particularmente influente, uma vez que, "[...] para a maioria das pessoas hoje, o conhecimento que nós temos dos fatos que acontecem além do nosso meio social imediato é, em grande parte, derivado de nossa recepção das formas simbólicas mediadas pela mídia" (THOMPSON, 2000, p. 285). Sendo assim, optei aqui por discutir como ela constrói os problemas sociais do futebol. Mais exatamente, analisei quais aspectos do futebol foram tipificados como problemáticos em editoriais da Folha de S. Paulo (a partir daqui, FSP) durante o período de 2008 a 2017 e interpretei o caráter ideológico potencial dessas tipificações.

Ao fazer isso, busquei contribuir para o desenvolvimento do debate acadêmico sobre comunicação e futebol resgatando a problemática das inter-relações entre sentido e poder ${ }^{4}$, sem, contudo, me guiar pelo prisma marxista-althusseriano,

3 Construtores de problemas sociais, em uma tradução livre.

4 Esta foi fundamental até os anos 1980, quando dominava a perspectiva crítica (HELAL, 2011). 
marcante nas primeiras produções da área. Entre elas, o livro Futebol: ideologia do poder, de Roberto Ramos (1984), que defendia a tese de que o futebol era um Aparelho Ideológico de Estado, uma vez que mistificaria as relações de produção, legitimando o capitalismo. Com efeito, a fim de captar o seu espírito crítico e, ao mesmo tempo, evitar alguns de seus perigos teórico-epistemológicos, adotei um enfoque mais construtivo: o conceito de ideologia proposto por John $\mathrm{B}$. Thompson (2000), sintetizado a seguir.

\section{Conceito de ideologia}

Em Ideologia e Cultura Moderna, Thompson (2000) retraça os contornos históricos do conceito de ideologia, distinguindo dois tipos gerais de concepções: as neutras, que entendem que a ideologia é um aspecto da vida social entre outros, não sendo nem mais nem menos atraente do que qualquer outro, e as críticas, que entendem que ela carrega consigo um criticismo implícito. Inserindo-se nesse segundo grupo de concepções, o professor e pesquisador da Universidade de Cambridge entende que uma forma simbólica pode ser considerada ideológica quando, sob determinadas circunstâncias, estabelecer e sustentar relações de dominação, entendendo por dominação relações de poder sistematicamente assimétricas. Nas suas palavras:

[...] podemos falar de dominação quando grupos particulares de agentes possuem poder de uma maneira permanente, e em grau significativo, permanecendo inacessível a outros agentes, ou a grupos de agentes, independentemente da base sobre a qual tal exclusão é levada a efeito (THOMPSON, 2000, p. 80).

A proposta de Thompson (2000) é particularmente construtiva, pois evita uma tendência, prevalente na literatura, de pensar a ideologia como uma característica ou atributo intrínseco de certas formas simbólicas ou sistemas simbólicos, tais como o conservadorismo, o comunismo, o liberalismo etc. Em sua proposta, nenhuma forma simbólica é ideológica ou contestatória em si mesma: se ela é ideológica ou contestatória, e o quanto o é, depende da maneira como é usada e entendida em contextos sociais específicos. Por essa razão, pode levar-nos “[... ] a olhar uma forma simbólica ou um sistema como ideológico num contexto e como radical, subversivo, contestador noutro" (THOMPSON, 2000, p. 18). Mais ainda: pode levar-nos também a considerar uma mesma forma simbólica como ideológica sob certos aspectos e como contestatória sob outros. 
Outro ponto importante da proposta de Thompson é que, para o autor, a dominação de classe é apenas um eixo da desigualdade e da exploração no mundo atual. De modo algum, é a única forma de dominação e subordinação. Assim,

ao estudar a ideologia, podemos nos interessar pelas maneiras como o sentido mantém relações de dominação de classe, mas devemos, também, interessar-nos por outros tipos de dominação, tais como as relações estruturadas entre homens e mulheres, entre grupo étnico e outro, ou entre estados-nação hegemônicos e outros estados-nação localizados à margem do sistema global (THOMPSON, 2000, p. 78).

Além de se interessar pelas mais diferentes formas de dominação e opressão, o conceito de ideologia desenvolvido por Thompson (2000) rechaça a ideia de que toda ideologia seja intrinsecamente ilusória - colocando o seu caráter enganador apenas como uma possibilidade contingente. Afinal, trata-se de uma concepção política de ideologia - uma vez que traz para o seu âmago a questão do poder - e não epistemológica - uma vez que nada diz acerca da questão da verdade, ou melhor, de como conhecemos o mundo social.

\section{Metodologia da interpretação}

Uma vez esclarecido o conceito de ideologia que embasou este artigo, cabe apresentar a metodologia adotada. Baseando-me na metodologia de interpretação proposta por Thompson (2000) - a hermenêutica de profundidade -, organizei a pesquisa em três etapas, que constituem dimensões analiticamente distintas de um processo interpretativo complexo. Na primeira etapa, descrevi o contexto sócio-histórico de produção, circulação e recepção dos editoriais que constituíram o corpus deste trabalho. Para tanto, realizei revisão de literatura no Google Scholar, na Scientific Electronic Library Online (SciELO), no Banco de Teses e Dissertações da Coordenação de Aperfeiçoamento de Pessoal de Nível Superior (Capes) e no meu arquivo particular. Os descritores utilizados nessa busca variaram de acordo com o modo de organização e a terminologia de cada base de dados.

Na segunda etapa, analisei as características estruturais do corpus do trabalho. Esse foi composto pela totalidade dos editoriais (75) que versavam sobre questões relacionadas ao futebol brasileiro publicados pela FSP no período 2008-2017. A opção por limitar o período estudado a dez anos deve-se à amplitude do corpus e ao fato de as mudanças no discurso da FSP ao longo 
das décadas transcender o objeto deste estudo, ainda que a análise dessas mudanças seja cientificamente relevante.

Por sua vez, a opção por me debruçar sobre a FSP justifica-se pelo fato de esse jornal ser uma referência no País, com grande circulação. Fazendo uso das palavras de Bourdieu (1997, p. 60-61): é "[...] suficientemente grande por sua tiragem para ser um poder do ponto de vista dos anunciantes e suficientemente dotado de capital simbólico para ser uma autoridade".

Já a opção por analisar editoriais justifica-se não por conta de

[...] uma eventual atenção massiva que, na prática, o grande público não lhes dedica (apenas uma pequena parte dos leitores Ihes dedica seu tempo), mas, por um lado, do fato de que os políticos os leem, com a concomitante capacidade de influência que isto comporta. $E$, por outro lado, do fato de quem determina o conteúdo dos editoriais - a direção, com ou sem os chefes de redação - é também quem determina em última instância a primeira página - que com frequência constitui toda uma tomada de posição política - e determina, também largamente, as orientações das manchetes das páginas interiores. Tanto as manchetes da primeira página como as das páginas interiores são de suma importância na hierarquia jornalística da informação e têm uma grande influência na opinião pública5 (GIRÓ; JARQUE, 2007, p. 18, tradução nossa).

O levantamento dos editoriais foi feito no acervo digital da FSP, durante os meses de julho e agosto de 2018. A fim de refinar os resultados e encontrar mais facilmente o material desejado, recorri à ferramenta "busca avançada". Com isto, foi possível cruzar as palavras-chave "futebol" e "editorial" e limitar a investigação ao primeiro caderno e ao período de $10^{\circ}$ de janeiro de 2008 a 31 de dezembro de 2017.

A despeito de ter utilizado esses filtros, os resultados apresentaram diversos textos que nada tinham a ver com o escopo da pesquisa. Com efeito, tive de realizar um longo e fastidioso trabalho de seleção manual dos artigos. $O$

5 Do original: [...] no se deriva de una eventual atención masiva que, en la práctica, el gran público no les dedica (sólo una pequeña parte de los lectores les dedica su tiempo), sino, por una parte, del hecho de que los políticos sí que los leen, con la concomitante capacidad de influencio que ello comporta. Y, por otra, del de que quien determina el contenido de los editoriales - la dirección, con o sin los jefes de redacción - es también quien determina en última instancia la portada - que con frecuencia constituye toda una toma de posición política - y determina, también en grandes líneas, las orientaciones de los titulares de las páginas interiores. Tanto los titulares de portada como los de las páginas interiores son de suma importancia en la jerarquía periodística de la información y tienen una gran influencia en la formación de la opinión pública. 
primeiro passo foi verificar se os textos apresentados no resultado da busca realmente eram editoriais (muitos não eram) e o segundo, se tratavam, de fato, de questões relativas ao futebol.

Uma vez selecionados os editoriais que constituíram o corpus deste trabalho, salvei-os no computador e os li na íntegra. Feito isso, submeti-os a uma análise de discurso (GIRÓ, 2007). Para realizar essa análise, elaborarei um quadro de sistematização (Quadro 1), a fim de facilitar a organização das informações. Esse foi estruturado em 75 linhas horizontais (uma para cada editorial) e sete colunas verticais.

Em relação a essas últimas, duas apresentavam informações "técnicas" das publicações, como o título e a data. Uma indicava o "pano de fundo" contra o qual os editoriais foram elaborados (por exemplo: se a publicação ocorreu após a revelação de um escândalo de corrupção, em vésperas de uma Copa do Mundo, em seguida a um episódio de violência etc.). Outra destacava a macroproposição semântica de cada texto, que manifestava o seu argumento central e dava coerência $a e^{6} e^{6}$. $E$ as últimas três apontavam para as condições consideradas, explícita ou implicitamente, como problemáticas, suas causas e soluções.

Quadro 1 - Modelo de quadro de sistematização dos editoriais

\begin{tabular}{|c|c|c|c|c|c|c|}
\hline Título & Data & Contexto & $\begin{array}{c}\text { Argumento } \\
\text { central }\end{array}$ & $\begin{array}{c}\text { Condições } \\
\text { problemáticas }\end{array}$ & Causas & Soluções \\
\hline Editorial 1 & & & & & & \\
\hline Editorial 2 & & & & & & \\
\hline Editorial 75 & & & & & & \\
\hline
\end{tabular}

Fonte: Elaborado pelo autor.

A produção desse quadro envolveu um complexo processo de categorização, que buscou agrupar, por analogia, diversos temas em grandes categorias, que foram revistas várias vezes. Por exemplo: uma das condições identificadas como problemáticas foi a corrupção. Sob esse rótulo, agrupei condições como a fraude, a manipulação desportiva e a falta de transparência, além da própria corrupção. Por um lado, o referido processo perde de vista a particularidade do conteúdo

\footnotetext{
6 Em geral, as macroproposições foram expressas no título e nas conclusões.

7 Importante destacar que apenas parte dos editoriais oferece uma explicação para essas condições e/ ou propõe alguma medida.
} 
dos materiais examinados; por outro, permite organizá-los e representá-los de forma simplificada - o que é particularmente relevante para este trabalho, que investiga um número grande de textos.

Na terceira etapa, indiquei como os conteúdos dos editoriais e a forma como são simbolicamente construídos podem estar associados a modos gerais de operação da ideologia e, consequentemente, servir a relações de dominação. Para tanto, empreendi uma síntese, por construção criativa, dos resultados das duas etapas anteriores (THOMPSON, 2000). A seguir, sintetizo os da primeira.

\section{Contexto de produção, circulação e recepção dos editoriais}

A FSP é um jornal editado na cidade de São Paulo, com irradiação nacional, e pertence ao Grupo Folha, um dos principais conglomerados de mídia do País. 0 jornal foi fundado em 1921, com o nome de Folha da Noite, esperando atrair leitores na classe trabalhadora e média urbana. Com isso, buscava fazer frente ao então principal jornal da cidade, o Estado de S. Paulo, de posição mais conservadora. Em 2015, a FSP tinha a terceira maior média de circulação impressa (189.254) e a maior digital (146.641) do País (ASSOCIAÇÃO NACIONAL DE JORNAIS, 2015).

De acordo com o seu Novo Manual da Redação (1998), a FSP se propõe a realizar um jornalismo apartidário e pluralista. Esses princípios, todavia, são questionados interna e externamente, pois são difíceis de se garantir dentro da estrutura interna do próprio jornal, "[...] pela própria diversidade de jornalistas e de leituras da realidade orientadas por recortes nem sempre explícitos" (ANDRADE, 2004, p. 72). Ademais, como qualquer empresa, a FSP precisa seguir os ditames do mercado. Com efeito, ainda que tenha como lema ser "um jornal a serviço do Brasil", o seu interesse principal é atender às necessidades de informação de seus próprios leitores, que constituem um segmento muito específico da população: em sua maioria, estudantes ou pessoas com Ensino Superior, das classes A e B, com até 39 anos (ANDRADE, 2004).

A fim de atender às necessidades de informação desse público (e garantir, assim, uma fatia importante do mercado jornalístico), a FSP deve ter apelo junto a ele. Essa exigência tende a influenciar os seus critérios de pauta, ou seja, quais assuntos entrarão na ordem do dia e como entrarão. Afinal, a hipotética opção por chocar os seus leitores - com notícias e, principalmente, opiniões que possam dividi-los, exclui-los e lhes causar mal-estar - pode reduzir a sua venda e colocar em risco a sua própria existência. Não à toa, conforme 
Bourdieu (1997), os jornais tendem a escolher os seus objetos de acordo com as categorias de percepção do receptor.

Um objeto do conhecimento, segundo o sociólogo francês, não é, todavia, algo dado, mas socialmente construído. "O princípio dessa construção é o sistema de disposições duráveis e aplicáveis a qualquer situação, 'estrutura estruturada' predisposta a operar como 'estrutura estruturante', enquanto princípio gerador de práticas e representações, o habitus" (BARROS FILHO; MARTINO SÁ, 2003, p. 115). Tais disposições são construídas pelo jornalista durante a sua trajetória no próprio campo jornalístico. É lá onde ele apreende a se antecipar às (supostas) expectativas de seus leitores e definir, sem necessidade de um cálculo consciente, o que é jornalisticamente importante informar.

Essa definição (e a própria circulação do discurso jornalístico), portanto, não é livre, mas limitada, controlada. Existe uma ordem social do discurso jornalístico, que estabelece que tipos de discursos podem ser produzidos e em quais contextos. Que estabelece os discursos autorizados e os desautorizados. Os legitimados e os deslegitimados. Os majoritários e os minoritários (ROJO, 2004). Essa ordem, por sua vez, é o produto de uma série de pressões exercidas pela lógica concorrencial do próprio campo jornalístico, como a da urgência.

A concorrência entre os jornais é expressa pela corrida por ser o primeiro, pelo furo. Não à toa, o Novo Manual de Redação da FSP (1998) destaca o ineditismo como um critério jornalístico relevante. Por conseguinte, há objetos que se impõem aos leitores porque se impõem aos jornalistas pela concorrência com outros veículos. A lógica da concorrência leva os jornalistas a fazerem coisas que não fariam caso seus pares-concorrentes não existissem. Mesmo que, para demarcar a sua diferença, um jornal não pode ficar indiferente àquilo que é noticiado pelo concorrente. É preciso abordar o acontecimento noticiado, nem que de alguma outra forma. Essa espécie de jogo de espelhos que se refletem mutuamente produz um formidável efeito de barreira, uma espécie de censura imposta pelo próprio campo jornalístico, que tende a homogeneizá-lo (BOURDIEU, 1997).

Diante do exposto, é possível conjecturar que os editoriais analisados foram produzidos a partir de uma série de regras e convenções, muitas não formuladas, informais e imprecisas, que dirigiram as ações dos seus redatores. Ademais, foram produzidos para receptores que não estavam fisicamente presentes no momento da sua produção. Por mais que a FSP tenha um perfil do seu leitor - por meio de pesquisas do Datafolha, dos comentários deixados no site e pela venda das assinaturas -, o processo de produção de seus editoriais é, ainda assim, marcado 
por certa indeterminação. Em última instância, não há um monitoramento direto e contínuo das audiências (THOMPSON, 2000).

Em geral, entende-se que as audiências de um jornal são as pessoas comuns que o leem. No entanto, quando focalizamos a mídia como uma das arenas de construção de problemas sociais, é preciso ampliar a compreensão de quem são seus receptores e voltar a atenção para aquelas pessoas que ocupam posições institucionais capazes de ser ouvidas e, no caso específico deste trabalho, influenciam os rumos do futebol brasileiro, debatendo e formulando as pautas das políticas públicas voltadas a eles (ROSEMBERG; ANDRADE, 2007).

\section{Análise dos editoriais e interpretação da ideologia}

À luz desse contexto, analisei e interpretei o potencial ideológico do material selecionado, cujos resultados apresento neste tópico. Começo fazendo um panorama geral desse material. Entre 2008 e 2017, a FSP publicou 75 editoriais que versam sobre futebol - o que dá uma média de 7,5 editoriais por ano. Desse total, apenas 7 editoriais ( $9 \%$ ) abordam, em alguma medida, questões relativas ao que ocorre no "palco do jogo", tais como: desempenho de jogadores, erros de arbitragem e controvérsias relativas ao resultado da partida. Em geral, tais questões são reservadas à seção de Esporte. Com isso, podemos dizer que, quando o futebol alcança o topo da hierarquia da relevância jornalística, isso ocorre principalmente por meio de seus bastidores e, em particular, dos conflitos que neles ocorrem.

Outro aspecto importante de ser destacado é que o futebol discutido nos editoriais é o masculino, ainda que as mulheres protagonizem há muito tempo histórias nesse esporte. Prova disto é que apenas 1 editorial (1,3\%) menciona, de passagem, a necessidade da Confederação Brasileira de Futebol (CBF) desenvolver o futebol feminino. A constatação referente à invisibilidade desse futebol nos editoriais da FSP corrobora os resultados da pesquisa de Goellner (2005) - para quem a mídia confere muito pouco espaço a esse futebol - e é particularmente relevante para a análise da ideologia. Afinal, ao manter o futebol feminino na penumbra, esses editoriais contribuem para conservar as desigualdades entre homens e mulheres em um espaço de sociabilidade criado e mantido sob o domínio masculino.

Também é importante salientar que os editorias abordam o futebol profissional, e não aquele praticado como uma atividade de lazer. Nesse contexto, importam, basicamente, aquelas questões relativas à organização do espetáculo futebolístico, feito para uma ampla massa de torcedores-consumidores. Os problemas referentes 
a essa organização são vistos, implicitamente, como manifestações patológicas, que devem ser extirpadas do futebol-espetáculo. O problema, portanto, não estaria na própria natureza desse futebol, ou seja, na transformação do futebol em um "grande-negócio", regido pela lógica neoliberal (LOPES; HOLLANDA, 2018), mas no funcionamento imperfeito de suas engrenagens. Não à toa, uma das soluções propostas é a adoção de "modelos" ou "padrões" empresariais de gestão. "Modelos" e "padrões" que envolvem, como é explicitado no editorial "Clubes endividados" (13/8/2012), transformar os clubes em empresas.

Uma categoria importante aqui é a de "modernidade". Em alguns editoriais - tais como, "Hora de virar o jogo" (13/7/2014), "A seleção gira em falso" (23/7/2014) e "Resgatar a imagem" (9/3/2016) -, a FSP defende a "modernização" do futebol brasileiro, sendo que os dirigentes seriam, nas palavras do jornal, "anacrônicos" e "autocráticos", constituindo um "obstáculo" a esse processo. Em outras palavras: seriam um acidente no processo de hipermercantilização do futebol, ameaçando a sua (suposta) racionalidade. O problema seria, portanto, o descompasso existente entre as práticas desses atores - representadas como arcaicas - e uma situação histórica nova: a transformação do futebol em um "grande negócio".

Por um lado, podemos dizer que tais editoriais possuem - em um contexto marcado por escândalos de corrupção, estádios vazios, calendários problemáticos, clubes endividados e evasão de craques para o exterior - certo caráter crítico, na medida em que denunciam aqueles que são os responsáveis por assegurar o funcionamento do espetáculo futebolístico. Esse caráter é reforçado na defesa, expressa no editorial "Virar o jogo" (9/2/2014), pela participação dos jogadores no processo de transformação do futebol brasileiro. Afinal, tal participação implica a democratização da estrutura de poder do universo do futebol.

Por outro lado, podemos dizer que a FSP, implicitamente, aceita a hipermercantilização do futebol como um dado da realidade, naturalizando uma lógica que "[...] alarga o espaço dos interesses do capital no universo do futebol, ao mesmo tempo que encolhe os diretos dos torcedores" (LOPES; HOLLANDA, 2018, p. 228). Ao naturalizar essa lógica, o jornal deixa de problematizá-la, criando uma agenda significativamente diferente da de outro claim-maker: os torcedores-ativistas. Nos últimos anos, surgiram vários movimentos e coletivos de torcedores que têm pautado, entre outras coisas, a defesa de uma tradição popular de torcer, a criação de setores populares nos estádios e o barateamento dos ingressos. Ao ignorar essas pautas e, por conseguinte, a exclusão dos pobres do espetáculo futebolístico, podemos afirmar que os editoriais são potencialmente ideológicos. 
Não causa surpresa que, nesse contexto em que o futebol-espetáculo, transformado em mercadoria, é aquele que possui visibilidade, os megaeventos esportivos (sobretudo os realizados no Brasil) tenham tido um amplo destaque. Conforme mostra o Gráfico 1, 36 editoriais (48\%) foram publicados no ano da Copa do Mundo no Brasil ou no ano anterior, quando foi realizada a Copa das Confederações, que serviu de teste para a primeira - sendo que 8 editoriais $(10,6 \%)$ foram publicados durante a realização da Copa. Esse número é maior do que o número médio de editoriais por ano $(7,5)$ e significativamente maior do que o número médio de editoriais por ano $(4,8)$ se desconsiderarmos 2013 e 2014.

Gráfico 1 - Distribuição dos editoriais por ano

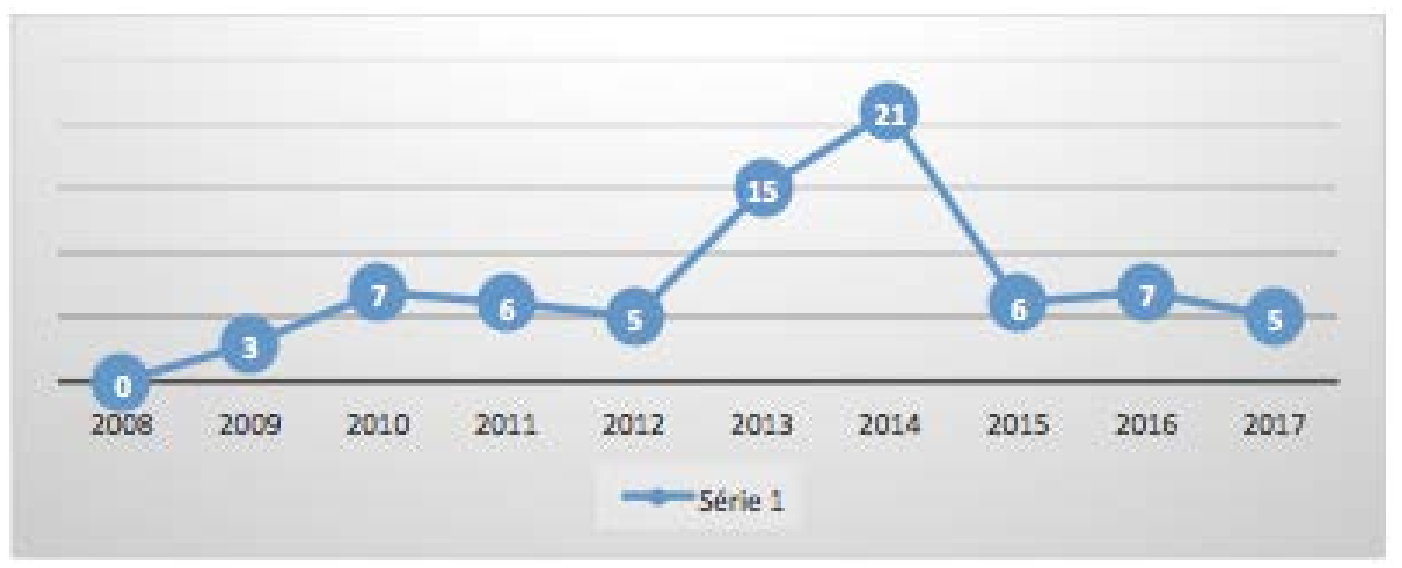

Fonte: Elaborado pelos autores com dados da pesquisa.

A percepção de que, nos anos pesquisados, o futebol brasileiro ganhou destaque principalmente quando associado a um megaevento esportivo é reforçado pelo fato de 40 editoriais $(53,3 \%)$ tratarem, de alguma forma, de assuntos relacionados às copas do mundo, copas das confederações e/ou olimpíadas. Cabe destacar, todavia, que não é só o campo jornalístico que tem conferido importância aos megaeventos esportivos, o próprio campo acadêmico da comunicação tem produzido livros, artigos e dossiês sobre o tema, indicando que há uma valorização comum do tema, devido, muito provavelmente, às suas implicações econômicas, culturais, sociais, urbanas e comunicacionais.

Ao abordar esses megaeventos, a FSP mostrou forte preocupação com a sua organização, infraestrutura e custos. Seu "legado" também foi objeto de dúvida e crítica. Esta foi expressa por meio de categorias depreciativas como "elefante branco", utilizada para designar os estádios que custaram muito dinheiro, mas que não teriam/ tiveram muita serventia. No editorial "Elefantes 
quase brancos" (7/1/2017), o jornal relaciona a subutilização de várias arenas construídas para a Copa do Mundo de 2014 à escolha de um grande número de cidades-sedes (12 no total). A escolha de tantas cidades serviria para contemplar os interesses políticos de Luiz Inácio Lula da Silva, presidente da República, durante a escolha das cidades-sede.

Ainda que a escolha de 12 sedes tenha sido controversa e o apoio dado por Lula a essa escolha possa ser objeto de (várias) críticas, o argumento da FSP é incoerente. Afinal, parte da constatação de que vários estádios estão subutilizados, incluindo o Maracanã, que, antes da Copa do Mundo de 2014, jamais havia sido visto como um potencial "elefante branco". Ao contrário, sempre fora retratado pela mídia especializada como o maior "templo" do futebol brasileiro. Consequentemente, a sua subutilização - como a de outros "templos", como a Fonte Nova, em Salvador - não possuí nenhuma relação com a escolha de 12 cidades-sedes. Com efeito, a conclusão do editorial serve mais para expurgar a figura do ex-presidente Lula, retratado no texto como populista e irresponsável, do que para explicar a subutilização dos estádios construídos ou reformados. Problema que envolve não apenas um único ator, mas uma série de agentes e instituições públicas e privadas, com interesses, muitas vezes, pouco republicanos.

Outras questões amplamente abordadas foram a da corrupção e/ou da falta de transparência na gestão de entidades esportivas e/ou na construção e reformas de estádios, mencionadas em 25 editoriais (33,3\%). A preocupação da própria Folha de S. Paulo com essas questões não é uma novidade. A título de exemplo: em 1999, o jornal iniciou uma série de reportagens investigativas sobre o contrato entre a Nike e a CBF, que mobilizou a instalação, em 2000, de uma Comissão Parlamentar de Inquérito (CPI) na Câmara dos Deputados para investigar a legalidade de tal contrato (RIBEIRO, 2007).

É importante recordar que, no decênio examinado, o Brasil vivenciou uma série de protestos contra a corrupção. Um marco importante foram as Jornadas de Junho de 2013, ocorridas nas vésperas da Copa das Confederações. Inicialmente restritas a alguns grupos e movimentos de esquerda - como o Movimento Passe Livre (MPL) -, que se contrapunham ao aumento nas tarifas do transporte público, essas manifestações acabaram ganhando forte adesão da população, fragmentando-se em uma miríade de demandas, que incluíam o fim da corrupção e o controle dos gastos com os megaeventos esportivos que se aproximavam.

Dois anos depois, vários protestos foram realizados pelo País reivindicando o impeachment da então presidenta da República, Dilma Rousseff, e responsabilizando seu partido (PT) por uma série de escândalos de corrupção, como o da 
Petrobrás. No ano subsequente, algumas torcidas organizadas - especialmente os Gaviões da Fiel, do Corinthians - iniciaram, dentro e fora dos estádios, uma série de protestos contra, entre outros atores, a Federação Paulista de Futebol (FPF) e a CBF, acusadas de corrupção, e contra o então presidente da Assembleia Legislativa de São Paulo, Fernando Capez (PSDB), acusado de fazer parte de um esquema de desvios e superfaturamento de compras de alimentos para as escolas públicas de São Paulo (LOPES; HOLLANDA, 2018).

Com efeito, ao iluminar uma condição - a corrupção - experimentada como insatisfatória por parte significativa da população, fiscalizando a ação dos agentes do Estado e das associações futebolísticas, os editoriais representam uma forma de crítica ao status quo futebolístico. Por outro lado, ao praticamente não apresentarem soluções para a sua transformação, os editoriais ajudam a fazer crer que ela é permanente e imutável, podendo levar o leitor a se resignar com a situação - o que pode contribuir para mantê-la.

Para agravar, nos (poucos) casos em que os editoriais mencionaram soluções, elas, com certa frequência, eram vagas - tais como aumentar o controle e a transparência -, pouco contribuindo para qualificar o debate público em torno da questão. Um dos raros editoriais a abordar uma medida concreta foi o "Corrupção em campo", de 17/6/2011, que se posicionou contra a aprovação, pelo Senado Federal, do Regime de Diferenciação de Contratações tal como estava, pois, segundo o jornal, isso poderia ajudar a acobertar atos de corrupção e fraude.

Outra condição problematizada foram os confrontos violentos envolvendo torcedores de futebol. Essa foi mencionada em 10 editoriais (13,3\%). Assim como no caso da corrupção, poucos editoriais discutiram propostas mais concretas. A maior parte deles limitou-se a defender que a solução passaria pelo fim da impunidade, criando "[...] mecanismos para banir para sempre os arruaceiros dos estádios de futebol", como defende o editorial "Corinthians sem torcida" (8/3/2013).

Este clamor da imprensa pelo fim da impunidade no futebol não é uma novidade, já se manifestando na década de 1950 (HOLLANDA, 2009). Na década de 1990, todavia, ele acentua-se, devido à ocorrência de graves incidentes no futebol brasileiro, como a chamada "Batalha Campal do Pacaembu", em 1995. Neste episódio, torcedores organizados do Palmeiras e do São Paulo invadiram o gramado e se enfrentaram violentamente com paus, pedras e outros artefatos, resultando na morte de um torcedor e em uma centena de feridos (LOPES, 2012).

Tal clamor sugere uma sobrecarga de expectativa da FSP em relação ao poder da lei. Sobrecarga já identificada na tese de Lopes (2012) e que vem ao encontro da ideia moderna de que o combate ao crime deve ser realizado por 
meio do estabelecimento de um marco legal abstrato e logicamente erigido e de uma resposta reativa ao delito. Em outras palavras: os confrontos seriam resolvidos de "cima para baixo". Sua solução estaria, portanto, nas mãos dos criadores e aplicadores de leis.

De certa forma, podemos dizer que, implicitamente, essa ideia se apoia no conceito sociológico de anomia. Afinal, conforme Chaui (2005, p. 127), esse se refere ao "[...] momento, acidental, em que as normas e as leis perdem o poder integrador, deixam de ser um eficaz cimento afetivo-moral e legal das relações sociais, fazendo reinar a violência, os conflitos políticos e sociais". Tal conceito, de acordo com a filósofa, é central para a construção do "mito da não violência brasileira". Mito que se apropria, segundo ela, da distinção entre arcaísmo e modernidade, localizando os agentes violentos no primeiro período. Esses seriam os responsáveis por perturbar a ordem social moderna, (supostamente) racional e não violenta. Seriam o vício, o feio, o imundo, o sem lei.

No debate público sobre violência no futebol, os torcedores organizados ocupam essa posição. Conforme Lopes (2013), eles são habitualmente representados pela mídia como "vagabundos", "marginais", "arruaceiros", "gangues travestidas de torcedores". Tais torcedores protagonizariam cenas de "vandalismo", "barbárie", "selvageria". Nos editoriais analisados, esse conjunto de categorias foi, mais uma vez, utilizado - inclusive, no título, como foi o caso do editorial "Arenas da barbárie" (11/12/2013).

Nesse mesmo editorial, a briga entre torcedores organizados do Vasco e do Atlético-PR, em Joinville (SC), foi taxada de "selvageria". Termo que também foi empregado no editorial "Futebol de outro mundo" (22/2/2015). Por sua vez, o editorial "Tragédia no futebol" (10/4/2016) fala em "barbárie entre torcidas", ao mencionar as 103 vidas perdidas desde 2010 devido a confrontos envolvendo torcedores. Já no editorial "Cúmplices da violência" (1/11/2014), as torcidas organizadas são retratadas como "facções travestidas de torcidas". Por fim, no editorial "Virar o jogo" (9/2/2014), foram classificadas como uma "horda".

Se consultarmos um dicionário, veremos que "horda" significa "selvagem", "bando indisciplinado", "multidão desordenada", "turba". Em outras palavras, que evoca a ideia de irracionalidade. $O$ engajamento dos torcedores organizados em embates corporais e armados seria, pois, sem propósito. Além de desviar a atenção da(s) lógica(s) por detrás desses embates - amplamente discutida pela literatura especializada, conforme Lopes (2012) -, essa representação serve para revestir esses torcedores com a imagem da maldade, já que nada explicaria aquilo que fizeram, a não ser a sua própria natureza, que seria violenta. 
Nesse sentido, podemos dizer que, nos editoriais analisados, a noção de natureza foi posta "[...] como critério e medida para a demarcação da violência como contra natureza" (CHAUI, 2005, p. 132). Os torcedores (considerados) violentos seriam uma monstruosidade, que penetraria o universo do futebol para destruir a sua boa natureza. Mais exatamente, para destruir a sua essência, ou seja, a rivalidade pacífica. Com isso, seguindo as análises de Thompson (2000), sustento que a ideologia opera, nesse caso, por meio da fragmentação. Afinal, tais editoriais criam, no seio da coletividade torcedora, uma separação "nós", pacíficos e ordeiros, e "eles", vândalos e violentos.

Aqui, a estratégia por meio da qual a fragmentação é expressa é do expurgo do outro. Afinal, essa estratégia, de acordo com Thompson (2000, p. 87), "[...] envolve a construção de um inimigo, seja ele interno ou externo, que é retratado como mau, perigoso e ameaçador e contra o qual os indivíduos são chamados a resistir coletivamente ou a expurgá-lo". O expurgo dos torcedores organizados, cabe destacar, é reforçado por outra estratégia: a da dissimulação. Afinal, os seus aspectos potencialmente positivos - como o fato de serem fonte de identidade, lazer e socialização para milhões de jovens - foram ocultados. Sequer, mencionados. O que significa que tais torcedores só são "dignos de nota" quando associados à violência.

Além de macular a sua imagem, desumanizando-os, o expurgo dos torcedores organizados possui outros efeitos. No editorial "Cúmplices da violência" (1/11/2014), por exemplo, serve para justificar e legitimar a defesa da ruptura do (suposto) apoio dos dirigentes esportivos a esses torcedores. Essa ruptura, diga-se de passagem, vai na contramão de alguns dos projetos mais bem-sucedidos de prevenção da violência no futebol, como o "Projeto Torcedor" (Fanprojekt) alemão, que investiu em projetos socio-pedagógicos dirigidos aos torcedores considerados mais "radicais", estabeleceu canais de comunicação com eles e valorizou os aspectos positivos de sua tradição torcedora (TEIXEIRA; LOPES, [2018]).

Não parece ser à toa que, no editorial "Tragédia no futebol" (10/4/2016), a FSP defende seguir o exemplo da Inglaterra. Afinal, esta adotou um modelo menos inclusivo do que o alemão, que excluiu a voz dos torcedores nas transformações do espetáculo futebolístico e apostou na "tolerância zero" com os hooligans, ampliando os mecanismos de vigilância e controle dentro e fora dos estádios. Tal modelo serviu de inspiração para o principal relatório da Comissão Nacional de Prevenção da Violência e Segurança nos Espetáculos Esportivos (Consegue), dos ministérios do Esporte e da Justiça, mencionado no editorial "Futebol de outro mundo" (22/2/2015). 
Em tal editorial, a FSP recomenda, entre outras coisas, deter e condenar os torcedores violentos. Recomendação que é feita em outros editoriais e radicalizada no intitulado "Corinthians sem torcida" (8/3/2013), que defende "[...] seguir o exemplo da Europa e criar mecanismos para banir para sempre os arruaceiros dos estádios de futebol". Esse tipo de punição parece pressupor a noção supramencionada de que os torcedores que participam de confrontos são naturalmente violentos e, por isso mesmo, irrecuperáveis e inassimiláveis pela sociedade.

Ao mesmo tempo em que aposta no endurecimento penal, a FSP não deixa de criticar os agentes de segurança. No já mencionado editorial "Futebol de outro mundo" (22/2/2015), também recomenda que a polícia seja melhor treinada. Esta, segundo o jornal, deve abandonar a retórica bélica e impedir que $o$ torcedor "vândalo" frequente os estádios. Essa recomendação é relevante para a análise da (crítica da) ideologia pois, de certa forma, coloca os responsáveis pela segurança como parte do problema, complexificando-o.

Também cabe salientar que a FSP dedicou atenção a outras formas de violência - ainda que não necessariamente assim denominadas -, como a homofobia ( 1 editorial), a xenofobia ( 1 editorial) e o racismo ( 3 editoriais). Ainda que esses 5 editoriais representem apenas $6,6 \%$ do total, eles não deixam de ser importantes por, de alguma forma, admitirem, nem que implicitamente, que há violência nas relações sociais estabelecidas no universo do futebol para além daquela praticada por torcedores que vandalizam, brigam e matam. Em outras palavras: a violência, no caso, não é localizada apenas em um único tipo de crime: o contra a propriedade (das coisas e da vida) (CHAUl, 2005). Mas, também, na discriminação, que, embora também possa matar, com frequência, opera no plano simbólico, não sendo percebida. Não à toa, é habitualmente vista com indiferença, quando não desprezada. E, como diria Vasilachis (2004, p. 111, tradução nossa), "é mister recordar que dói tanto a ferida como o desprezo, a chicotada como a indiferença"

É importante destacar, todavia, que a FSP apresentou apenas soluções para uma única forma de discriminação (a racial) e de forma vaga, como realização de campanhas, aplicação da lei e punição aos clubes, o que não contribui para mudar a ordem social vigente. Também cabe ressaltar que o machismo não foi problematizado em nenhum editorial, reforçando a ideia de que as mulheres e os problemas por elas enfrentados permanecem na penumbra na FSP, o que contribui para manter o universo do futebol sob domínio dos homens.

8 Do original: Es menester recordar que duele tanto la herida como el desprecio, el latigazo como la indiferencia. 


\section{Considerações finais}

Este artigo objetivou analisar quais aspectos do futebol foram tipificados como problemáticos em editoriais da FSP durante o período de 2008 a 2017 e interpretar o caráter ideológico potencial dessas tipificações. Ao realizar essa análise e interpretação, busquei mostrar que o futebol visibilizado nesse material é o masculino e que o machismo nas arquibancadas não é problematizado, o que contribui para sustentar as desigualdades entre homens e mulheres em um espaço dominado pelos primeiros. Nesse sentido, argumentei que tal material é potencialmente ideológico.

Também argumentei que ele é, da mesma forma, potencialmente ideológico na medida em que naturaliza a lógica neoliberal que move o futebol-espetáculo, não problematizando algumas de suas consequências, como a exclusão do torcedor pobre dos estádios. Outro aspecto importante de ser destacado é que, entre as condições problematizadas, a corrupção ganhou particular destaque nos editoriais examinados. Por um lado, esse destaque não deixa de representar uma forma de crítica à ordem social futebolística, vivenciada como insatisfatória. Por outro, ao apresentar poucas e vagas soluções para a questão, a FSP ajuda a ensejar a ideia de que ela é permanente e imutável, ajudando a manter tudo como está.

Além da corrupção, os confrontos violentos envolvendo torcedores foram pautados e discutidos. Nessa discussão, as torcidas organizadas foram, com frequência, construídas como um elemento irracional, que atrapalharia o (bom) andamento do espetáculo-futebolístico e contra o qual somos chamados a expurgá-lo. Não à toa, a FSP advoga o endurecimento penal e a adoção do modelo inglês, que aposta na exclusão dos torcedores considerados problemáticos. Os confrontos envolvendo torcedores, entretanto, não foram a única forma de violência abordada, a homofobia, a xenofobia e o racismo também foram mencionados, ainda que com menos destaque.

Para finalizar, destaco que a discussão em torno dessas formas de violência abre a possibilidade de compreendermos a violência no futebol no plural. Tratase de violências. Violências que não são um acidente, mas parte intrínseca das relações estabelecidas no universo futebolístico. Isso é particularmente importante para a análise da ideologia pois o mito da não violência se encarrega de negar as diversas formas de dominação engendradas pelas diferentes formas de desigualdades e injustiças estabelecidas no interior desse universo. E, uma vez estabelecida essa negação, o conflito passa a ser uma patologia, legitimando, 
consequentemente, a eliminação de todos aqueles que (supostamente) perturbam a (suposta) ordem e paz no futebol.

\section{Referências}

ALTHUSSER, L. Ideologia e Aparelhos Ideológicos de Estado (Notas para uma investigação). In: ZIZEK, S. (org.). Um mapa da ideologia. 5. ed. Rio de Janeiro: Contraponto, 2013, p. 105-142.

ANDRADE, L. Prostituição infanto-juvenil na mídia: estigmatização e ideologia. São Paulo: EDUC; São Paulo: FAPESP, 2004.

ANJ. Maiores jornais do Brasil. $1^{\circ}$ dez. 2015. Disponível em: http://www.anj.org.br/ maiores-jornais-do-brasil/. Acesso em: 14 nov. 2017.

BARROS FILHO, C.; SÁ MARTINO, L. M. O habitus na comunicação. São Paulo: Paulus, 2003.

BEST, J.; LOSEKE, D. R. (ed.). Social problems: constructionist readings. New York: Walter de Gruyter, 2003.

BOURDIEU, P. Sobre a televisão. Rio de Janeiro: Jorge Zahar, 1997.

CHAUI, M. Simulacro e poder: uma análise da mídia. São Paulo: Perseu Abramo, 2005.

FLORES, L. F. B. N. Na zona do agrião: algumas mensagens ideológicas do futebol. In: R. DaMatta (org.). Universo do futebol: esporte e sociedade brasileira. Rio de Janeiro: Pinakotheke, 1982, p. 43-58.

FOLHA DE S. PAULO. Novo manual da redação. São Paulo: Folha de S. Paulo, 1998. https://doi.org/10.11606/d.91.2019.tde-27032019-175408

FOLHA DE S. PAULO. Editorial - Corrupção em campo. 12 jun. 2011. Disponível em: https:// acervo.folha.com.br/leitor.do?numero $=18797 \&$ key word=campo\&anchor $=5711016 \& 0-$ rigem=busca\&pd=c141971b6faa7f3ee8f19714cab8b3f6. Acesso em: 26 nov. 2018.

FOLHA DE S. PAULO. Editorial - Clubes endividados. 13 ago. 2012. Disponível em: https://www1.folha.uol.com.br/opiniao/1136165-editorial-clubes-endividados.shtml. Acesso em: 26 nov. 2018.

FOLHA DE S. PAULO. Editorial - Corinthians sem torcida. 8 mar. 2013. Disponível em: https://www1.folha.uol.com.br/opiniao/2013/03/1242636-editorial-corinthians-sem-torcida.shtml. Acesso em: 26 nov. 2018.

FOLHA DE S. PAULO. Editorial - Arenas da barbárie. 11 dez. 2013. Disponível em: https://www1.folha.uol.com.br/opiniao/2013/12/1383850-editorial-arenas-da-barbarie. shtml. Acesso em: 26 nov. 2018. 
FOLHA DE S. PAULO. Editorial - Hora de virar o jogo. 13 jul. 2014. Disponível em: https://www1.folha.uol.com.br/opiniao/1136165-editorial-clubes-endividados.shtml. Acesso em: 26 nov. 2018.

FOLHA DE S. PAULO. Editorial - A seleção gira em falso. 23 jul. 2014. Disponível em: https://www1.folha.uol.com.br/opiniao/2014/07/1489817-editorial-a-selecao-gira-em-falso.shtml. Acesso em: 26 nov. 2018. https://doi.org/10.5007/1984-6924.2014V11n2p402

FOLHA DE S. PAULO. Editorial - Cúmplices da violência. 01 de nov. de 2014. Disponível em: https://acervo.folha.com.br/leitor.do?numero=20030\&keyword=Editorial\&anchor $=5968154 \&$ origem $=$ busca\&pd $=$ da66ego6742d4c1e7c2b8ceg8aif44d8. Acesso em: 26 nov. 2018.

FOLHA DE S. PAULO. Editorial - Futebol de outro mundo. 22 de fev. de 2015. Disponível em: https://acervo.folha.com.br/leitor.do?numero=20143\&keyword=Editorial\&anchor $=5981641 \&$ origem $=$ busca $\& p d=472 d 34$ b1f47766f461e $459 c 66269$ dac 2 . Acesso: em: 26 nov. 2018.

FOLHA DE S. PAULO. Editorial - Resgatar a imagem. 09 mar. 2016. Disponível em: https://www1.folha.uol.com.br/opiniao/2016/03/1747885-resgatar-a-imagem.shtml. Acesso em: 26 nov. 2018.

FOLHA DE S. PAULO. Editorial - Tragédia no futebol. 10 abr. 2016. Disponível em: https://www1.folha.uol.com.br/opiniao/2016/04/1759303-tragedia-no-futebol.shtml. Acesso em: 26 nov. 2018.

FOLHA DE S. PAULO. Editorial - Elefantes quase brancos. 07 jan. 2017. Disponível em: https://www1.folha.uol.com.br/opiniao/2017/01/1847781-elefantes-quase-brancos. shtml. Acesso em: 26 nov. 2018.

FREITAS, R. F.; LINS, F.; SANTOS, M. H. C. Megaeventos: uma alquimia incontrolável das cidades. Revista Logos, v. 1, n. 24, p. 1-13, 2014. Disponível em: file://C:/Users/ftplo/ Downloads/13129-44356-1-SM.pdf. Acesso em: 22 mar. 2019. https://doi.org/10.12957/ logos.2014.13129

GIRÓ, X. Enfoques analíticos críticos sobre el discurso de la cobertura informativa de conflictos. In: TELLESCHI, T.; SANDOVAL F, ANDRÉS, E. (coord.). Espacio y tiempo en la globalización: una visión de la transparencia en la información. Toluca: Universita' di Pisa y Comisión Estatal para el Acceso a la Información Pública del Estado de Sinaloa, 2007. p. 199-220. https://doi.org/10.17561/rej.n17.a7

GIRÓ, X.; JARQUE, J. M. El discurso editorial sobre inmigración de El País, La Vanguardia, El Periódico y Avui, desde El Ejido hasta la cumbre europea de Sevilla (19992000). In: ZAPATA-BARBEIRO, R.; VAN DIJK, T. (eds.). Discursos sobre la inmigración en España: los medios de comunicación, los parlamentos y las administraciones. Barcelona: Fundació CIDOB, 2007. p. 17-44. https://doi.org/10.18356/9ca2aoog-es 
GOELLNER, S. Mulheres e futebol no Brasil: entre sombras e visibilidades. Revista Brasileira De Educação Física E Esporte, v. 19, n. 2, p. 143-151, 2005. Disponível em: file://C:/ Users/ftplo/AppData/Local/Packages/Microsoft.MicrosoftEdge 8wekyb3d8bbwe/ TempState/Downloads/16590-Texto\%20do\%20artigo-19740-1-10-20120522\%20(1). pdf. Acesso em: 23 nov. 2018.

HELAL, R. Futebol e comunicação: a consolidação do campo acadêmico no Brasil. Comunicação, Mídia e Consumo, São Paulo, v. 08, n. 21, p. 11-38, 2011. Disponível em: http://revistacmc.espm.br/index.php/revistacmc/article/viewFile/208/205. Acesso em: 23 nov. 2018.

HOLLANDA, B. B. B. O clube como vontade e representação: o jornalismo e a formação das torcidas organizadas de futebol do Rio de Janeiro: 7 Letras, 2009.

HOLLANDA, B. B. B.; MELO, V. A. Apresentação. In: HOLLANDA, B. B. B.; MELO, V. A. (org.). $O$ esporte na imprensa e a imprensa esportiva no Brasil. Rio de Janeiro: 7 Letras, 2012, p. 15-19. https://doi.org/10.22456/1983-201x.37499

LOPES, F. T. P. Discursos sobre violência envolvendo torcedores de futebol: ideologia e crítica na construção de um problema social. 2012. 590 f. Tese (Doutorado em Psicologia Social) - Instituto de Psicologia da Universidade de São Paulo, São Paulo, 2012. Disponível em: file://C:/Users/ftplo/AppData/Local/Packages/Microsoft. MicrosoftEdge_8wekyb3d8bbwe/TempState/Downloads/lopes_do\%20(1).pdf. Acesso em: 23 nov. 2018. https://doi.org/10.11606/t.47.2012.tde-13072012-103725

LOPES, F. T. P. Dimensões ideológicas do debate público acerca da violência no futebol brasileiro. Revista Brasileira de Educação Física e Esporte. São Paulo, v. 4, n. 27, p. 597-612, 2013. Disponível em: http://www.scielo.br/scielo.php?pi$\mathrm{d}=\mathrm{S} 1807-55092013000400008 \&$ script=sci abstract\&tlng=es. Acesso em: 23 nov. 2018. https://doi.org/10.1590/s1807-55092013000400008

LOPES, F. T. P. Violência no futebol: ideologia na construção de um problema social. Curitiba: CRV, 2019. https://doi.org/10.24824/978854443115.3

LOPES, F. T. P.; HOLLANDA, B. B. B. Ódio eterno ao futebol moderno": poder, dominação e resistência nas arquibancadas dos estádios da cidade de São Paulo. Tempo, v. 24, n. 2, p. 207-232, 2018. Disponível em: http://www.scielo.br/scielo.php?script=sci abstrac$\underline{\text { t\&pid }=S 1413-77042018000200206 \& l n g=e n \& n r m=i s o}$. Acesso em: 23 nov. 2018. https:// doi.org/10.1590/tem-1980-542×2018v240202

LOVIOLO, H. Sociologia do esporte (futebol): conversações argumentativas. In: HELAL, R.; LOVISOLO, H.; SOARES, A. J. Futebol, jornalismo e ciências sociais: interações. Rio de Janeiro: EdUERJ, 2011. p. 11-32.

MARQUES, J. C. A "criança difícil do século" - algumas configurações do esporte no velho e no novo milênio. Comunicação, Mídia e Consumo, São Paulo, v. 8, n. 21, p. 93- 
112, 2011. Disponível em: http://revistacmc.espm.br/index.php/revistacmc/article/ view/212/209. Acesso em: 23 mar. 2019.

RAMOS, R. Futebol: ideologia do poder. Petrópolis: Vozes, 1984.

RIBEIRO, A. Os donos do espetáculo: história da imprensa esportiva no Brasil. São Paulo: Terceiro Nome, 2007.

ROJO, L. M. A frontera interior - análise crítica do discurso: um exemplo sobre o "racismo". In: IÑIGUEZ, L. (Coord.). Manual de Análise do Discurso em Ciências Sociais. Petrópolis, Editora Vozes, 2004. p. 206-257. https://doi.org/10.22409/resa2014.v7i1. a21178

ROSEMBERG, Fúlvia; ANDRADE, Marcelo. Infância na mídia brasileira e ideologia. In: JACÓ-VILELA Ana Maria; SATO, Leny (org.). Diálogos em Psicologia Social. Porto Alegre: Evangraf, 2007. p. 257-274.

SIMÕES, I. Clientes versus rebeldes: novas culturas torcedoras nas arenas do futebol moderno. Rio de Janeiro: Multifoco, 2017.

TEIXEIRA, R. C.; LOPES, F. T. P. Reflexões sobre o "Projeto Torcedor" alemão: produzindo subsídios para o debate acerca da prevenção da violência no futebol brasileiro a partir de uma perspectiva sociopedagógica. Revista de Antropologia - USP, v. 63, n. 3, 2018 (no prelo). https://doi.org/10.11606/2179-0892.ra.2018.152037

THOMPSON, J. B. Ideologia e cultura moderna: teoria social crítica na era dos meios de comunicação de massa. 4. ed. Petrópolis: Vozes, 2000.

TORO, C. A. O espectador como espetáculo: notícias das Torcidas Organizadas na Folha de S. Paulo (1970-2004). 2004. 150 f. Dissertação (Mestrado em Ciências Sociais) Instituto de Filosofia e Ciências Humanas, Universidade Estadual de Campinas, Campinas, 2004. https://doi.org/10.1590/s0104-71831997000200019

VAN DIJK, T. Discurso e poder. São Paulo: Contexto, 2008.

VASILACHIS DE GIALDINO, I. El lenguaje de la violencia en los medios de comunicación. Las otras formas de ser de la violencia y de la prensa escrita. In: PROGRAMA DE LAS NACIONES UNIDAS PARA EL DESARROLLO (Comp.). Aportes para la convivencia y la seguridad ciudadana. San Salvador: PNUD, 2004. p. 109-161. https://doi.org/10.2307/j. ctt22p7gf8.5 


\section{Dados do autor:}

Felipe Tavares Paes Lopes - lopesftp@gmail.com

Graduado em Filosofia pela USP e em Comunicação Social pela ESPM. Mestre e doutor em Psicologia Social pela PUC-SP e USP, respectivamente. Realizou estágio doutoral na UAB, Barcelona, e pesquisas de pós-doutorado na FEF-UNICAMP e CPDOC-FGV. Atualmente, é docente do Programa de Pós-graduação em Comunicação e Cultura da UNISO.

\section{Endereço do autor:}

Universidade de Sorocaba, Programa de Pós-Graduação em Comunicação e Cultura - $1^{\circ}$ Piso da Biblioteca Aluísio de Almeida, Cidade Universitária Professor Aldo Vannucchi - Rod. Raposo Tavares, Km 92.5 - Sorocaba (SP), Brasil 